\title{
The Practice Gap: National Estimates of Screening and Counseling for Alcohol, Tobacco, and Obesity
}

Paul R. Shafer, $M A^{1,2}$

Amanda Borsky, DrPH, MPP'

Quyen Ngo-Metzger, MD, MPH

Therese Miller, DrPH ${ }^{1}$

David Meyers, $M D^{1}$

'Agency for Healthcare Research and

Quality, Rockville, Maryland

${ }^{2}$ Department of Health Policy and Management, Gillings School of Global Public Health, University of North Carolina at Chapel Hill, Chapel Hill, North Carolina

\begin{abstract}
Tobacco use, lack of physical activity and poor diet, and alcohol consumption are leading causes of death in the United States. We estimated screening and counseling rates by using a nationally representative sample of adults aged 35 years and older with a preventive care supplement to the 2014 Medical Expenditure Panel Survey. Receipt of the recommended level of services ranged from nearly two-thirds ( $64.2 \%$ for obesity, $61.9 \%$ for tobacco use) to less than one-half $(41.0 \%$ for alcohol misuse). There is significant room for improving care delivery, but primary care practices probably also need additional resources to raise screening and counseling rates.
\end{abstract}

Ann Fam Med 2019;17:161-163. https://doi.org/10.1370/afm.2363.

\section{INTRODUCTION}

T obacco use, lack of physical activity and poor diet, and alcohol consumption are leading causes of death in the United States, and the US Preventive Services Task Force has developed recommendations targeted at reducing their prevalence. ${ }^{1,2}$ Screening and counseling for tobacco use, obesity, and alcohol misuse require 2 steps: patients must be screened for a behavior or condition, and clinicians must provide appropriate counseling for those screening positive. Prior research has demonstrated gaps in receipt of these screening and counseling services, ${ }^{3,4}$ but we do not know at a population level what percentage of adults are receiving the recommended services and whether the screening or counseling component is driving any practice gaps-the latter of which is critical for quality improvement efforts.

\section{METHODS}

We used the Preventive Care Self-Administered Questionnaire (PSAQ) from the 2014 Medical Expenditure Panel Survey (MEPS), sponsored by the Agency for Healthcare Research and Quality. ${ }^{5}$ MEPS is a nationally representative annual survey of approximately 30,000 individuals in more than 10,000 households, serving as a comprehensive source of measures of health status, health insurance coverage, health care use, and spending in the United States. ${ }^{6}$ The PSAQ was fielded in early 2015 and included 2,186 adults aged 35 years and older. Survey development included expert review by survey methodologists and the use of focus groups and cognitive, usability, and field testing. ${ }^{5}$ The survey instrument and documentation are available through the MEPS website. ${ }^{7}$

We estimated rates of screening and counseling for tobacco use (any use within past year), obesity (BMI $\geq 30$ ), and alcohol misuse (4 or more drinks on a day in the past year for women and 5 or more for men). Receipt of the recommended preventive service includes reporting being screened and, if screening positive, then also receiving counseling. Our estimates are weighted to be nationally representative, with standard errors adjusted to account for the complex survey design of the MEPS and the PSAQ subsample.
Paul R. Shafer, MA

Department of Health Policy and Management

Gillings School of Global Public Health University of North Carolina at Chapel Hill 135 Dauer Drive, Campus Box 7411

Chapel Hill, NC 27599

pshafer@unc.edu 


\section{RESULTS}

The overall rate of receipt of appropriate tobacco screening and counseling was $61.9 \%$ (Table 1). Of the approximately two-thirds $(66.2 \%)$ of adults who were screened for tobacco use, $21.6 \%$ used tobacco. Of these, almost three-quarters (71.1\%) received counseling or medication to help stop smoking. The overall rate of appropriate screening and counseling for obesity (64.2\%) was similar to the rate for tobacco. It was achieved in a very different way, however. More adults reported being screened for obesity $(78.6 \%)$, and of those screened, nearly $40 \%$ had a BMI of 30 or higher $(39.2 \%)_{i}$ however, only slightly more than one-half $(53.5 \%)$ of obese adults screened reported receiving counseling about weight management. The rate of receipt of appropriate screening and counseling for alcohol misuse was lower (41.0\%) than for either tobacco or obesity. Only about one-half of adults were screened for alcohol misuse $(48.5 \%)$, with onefifth $(20.0 \%)$ screening positive. Of these, less than one-quarter $(24.4 \%)$ reported receiving counseling to reduce their alcohol use.

\section{DISCUSSION}

These results remind us that there is significant room for improving the delivery of clinical preventive services for these drivers of morbidity and mortality, a finding that is consistent with prior studies. ${ }^{3,4}$ In 2018, the PSAQ will be fielded again in a larger subsample, allowing us to monitor progress in the receipt of clinical preventive services at a population level over time. Different solutions are probably necessary to increase the delivery of each of these services, given the varied profile of gaps in screening and counseling for these 3 conditions.

For example, quality improvement may require preparing teams to ensure delivery of effective weight loss counseling, whereas improving tobacco cessation may require additional attention to universal screening. Counseling can be provided within primary care or referred from primary care. Resources are available to guide integration of behavioral health in primary care and other ambulatory settings. ${ }^{8}$ Attention is needed to increase screening and counseling for alcohol misuse. Some promising strategies for increasing screening include the use of electronic medical reminders and panel management support. ${ }^{9}$ Primary care practices probably also need additional training and resources to improve overall screening and counseling rates for their patients..$^{10}$ Solutions may vary and should be tailored to the local environment to balance the competing demands of primary care. ${ }^{11-13}$

To read or post commentaries in response to this article, see it online at http://www.AnnFamMed.org/content/17/2/161.

Key words: primary health care; preventive medicine; preventive health services; tobacco use; obesity; alcohol drinking; counseling; health behavior

Submitted September 21, 2018; submitted, revised, December 4, 2018; accepted December 28, 2018.

Acknowledgments: This paper was supported as part of the Agency for Healthcare Research and Quality (AHRQ) intramural research program. The findings and conclusions in this document are those of the author(s), who are responsible for its content, and do not necessarily represent the views of AHRQ. No statement in this report should be construed as an official position of AHRQ or of the US Department of Health and Human Services.

Author contributions: P.R.S. drafted the manuscript; A.B., Q.N.-M., T.M., and D.M. provided feedback on the manuscript. The authors appreciate the efforts of Bidong Liu, Yanling Zhao, and Zhengyi Fang of Social \& Scientific Systems, Inc in the data production and preparation of the exhibit; Steven R. Machlin and Pradip Muhuri of AHRQ in providing technical assistance; and Russ Mardon, Shannon Fair, Phuong Hoang, and Mary Masters, currently or formerly of Westat, and Wilson Pace and Brandon Combs of the University of Colorado in helping to develop the PSAQ.

\section{References}

1. Mokdad AH, Ballestros K, Echko M, et al; US Burden of Disease Collaborators. The state of US health, 1990-2016: burden of diseases, injuries, and risk factors among US states. JAMA. 2018;319(14): 1444-1472.

2. U.S. Preventive Services Task Force. Recommendations for primary care practice. https://www.uspreventiveservicestaskforce.org/Page/ Name/recommendations/. Accessed Jun 21, 2018. 
3. Nichols J, Bazemore A. Winnable battles: family physicians play an essential role in addressing tobacco use and obesity. Am Fam Physician. 2014;89(11):872.

4. Maciosek MV, LaFrance AB, Dehmer SP, et al. Updated priorities among effective clinical preventive services. Ann Fam Med. 2017;15(1):14-22.

5. Borsky A, Zhan C, Miller T, Ngo-Metzger Q, Bierman AS, Meyers D. Few Americans receive all high-priority, appropriate clinical preventive services. Health Aff (Millwood). 2018;37(6):925-928.

6. Agency for Healthcare Research and Quality. Household component. https://meps.ahrq.gov/mepsweb/survey_comp/household.jsp. Accessed Nov 24, 2018

7. Agency for Healthcare Research and Quality. MEPS HC-173: 2014 preventive care self-administered questionnaire file. https://meps. ahrq.gov/mepsweb/data_stats/download_data_files_detail.jsp?cbo PufNumber $=$ HC-173. Published Dec 2016. Accessed Nov 24, 2018.

8. Korsen NBA, Peek CJ, Kathol R, et al. Integration Playbook. Rockville, MD: Agency for Healthcare Research and Quality; 2016.
9. Loo TS, Davis RB, Lipsitz LA, et al. Electronic medical record reminders and panel management to improve primary care of elderly patients. Arch Intern Med. 2011;171(17):1552-1558.

10. Cohen DJ, Balasubramanian BA, Isaacson NF, Clark EC, Etz RS, Crabtree BF. Coordination of health behavior counseling in primary care. Ann Fam Med. 2011;9(5):406-415.

11. Edwards ST, Marino M, Balasubramanian BA, et al. Burnout among physicians, advanced practice clinicians and staff in smaller primary care practices. J Gen Intern Med. 2018;33(12):2138-2146.

12. Taksler GB, Pfoh ER, Stange KC, Rothberg MB. Association between number of preventive care guidelines and preventive care utilization by patients. Am J Prev Med. 2018;55(1):1-10.

13. Jaén CR, Stange KC, Nutting PA. Competing demands of primary care: a model for the delivery of clinical preventive services. J Fam Pract. 1994;38(2):166-171.

\section{CHANGE-OF-ADDRESS FORM FAMNILY MEDICINE}

Please complete this form and mail to the following address or fax to Annals Circulation at 913-906-6080:

Annals of Family Medicine, Circulation Department, 11400 Tomahawk Creek Pkwy, Leawood, KS 66211-2680

Check if member of sponsoring organization:

$\begin{array}{ll}\square \text { AAFP } & \square \text { ABFM } \square \text { STFM } \square \text { ADFM } \\ \square \text { AFMRD } \square \text { NAPCRG } \square \text { CFPC }\end{array}$

ID number from label on your journal cover

OLD Information (Please print.)

\begin{tabular}{ll}
\hline Name \\
\hline Company (if applicable) \\
\hline Address (Street plus Apt or Ste) \\
\hline City & Postal Code (9-digit ZIP for US) \\
\hline Country & Fax \\
\hline Telephone & \\
\hline E-Mail & \\
\hline
\end{tabular}

NEW Information (Please print.)

\begin{tabular}{|c|c|}
\hline Name & \\
\hline Company (i & \\
\hline Address (St & \\
\hline City & State \\
\hline Country & Postal Code (9-digit ZIP for US) \\
\hline Telephone & Fax \\
\hline
\end{tabular}

